\section{Inhibiting Effect of Chlorpromazine on the Experimental Production of Liver Cancer}

Recentuy, Griffin, Rinfret and Corsigilia ${ }^{1}$ reported that development of hepatic tumours in rats fed on a diet containing 0.06 per cent 3 '-methyl-4-dimethylaminoazobenzene may be effectively inhibited by hypophysectomy. Chlorpromazine is a phenothiazine derivative, which is used medicinally as a potent depressant for the interbrain. Aron, Guelfi and Voisin ${ }^{2}$ reported an atonic effect of this drug on the sensibility of the pituitary gland induced by stress.

The present communication deals with the results of the subcutaneous injection of chlorpromazine on the incidence and growth of tumours induced by 4-dimethyl-aminoazobenzene. In these experiments chlorpromazine injection was begun with a dose of $100 \mu \mathrm{gm}$. in $1 \mathrm{ml}$. of cold sterile distilled water and continued at intervals of two days, increasing by $100 \mu \mathrm{gm}$. per dose after about every four injections. A group of fifteen rats of mixed breed weighing 70$153 \mathrm{gm}$. were fed for the first month with a diet containing 0.02 per cent 4-dimethyl-aminoazobenzene, during the second month with one containing 0.04 per cent, and thereafter with a diet containing 0.06 per cent, until the dose for each rat totalled about 500-600 $\mathrm{mgm}$. In addition, $1 \mathrm{ml}$. of distilled water was injected every two days over a period of six months (group 1). A second group of twenty rats was given the same diet but with in. jections of chlorpromazine (group 2). A third group consisted of fifteen rats fed on the basal diet without 4-dimethylaminoazobenzene but given chlorpromazine. The basal diet consisted of unpolished rice containing $2.71 \mathrm{mgm}$. riboflavin per $\mathrm{kgm}$. and $73.7 \mathrm{gm}$. protein per kgm., supplemented by unlimited quantities of water and some greenstuff, daily. The amounts of basal diet consumed totalled 1,011-1,154 gm. per rat. The experiments, which began on June 16, were terminated six months later.

During the course of this investigation, it was noted that, among the animals which received chlorpromazine until they died or those killed at the end of the experiment, rats weighing 70-100 gm. showed more decrease in weight and higher mortality due to respiratory infections than those weighing 110-153 gm., suggesting toxicity of the drugs Most of the thirteen rats which were given about 505$599 \mathrm{mgm}$. of 4-dimethyl-aminoazobenzene for a period of 162-183 days (group 1) developed hepatic cancer (Fig. 1). On the other hand, the group given chlorpromazine as well (group 2) showed careinoma of the liver in 1 out of 6 rats which survived the same period. Further, in group 1, the induced liver cancer attained considerable size after six months when compared with the livers of group 2, and metastases sometimes appeared in the abdominal lymph nodes and lungs. These results may suggest delay due to chlorpromazine in the formation of hepatic neoplasia induced by 4-dimethyl-aminoazobenzene.

Histologically, noticeable alterations were found in the hypophysis and adrenal glands as well as the liver. In the two groups treated with chlorpromazine, atrophy of the pituitary gland was noticed, and the anterior lobe consisted largely of the chief cells (chromorshobes) with the number of chromophils markedly decreased. In the adrenal glands, pycnosis of nucleus and vacuolation of cytoplasm were seen in the cortical cells. Parenchymal cells of the liver were somewhat atrophic and degenerative. Precan. cerous changes, such as nodular hyperplasia or cholangiofibrosis, were rarely seen except in one case where hepatoma developed, although cirrhotic changes of the liver were observed.

Recently, Peters, Gärtner and Krais ${ }^{3}$ have shown that a combination of radium therapy and chlorpromazine brings about in mice an increase in the effect of radiation on ascitic tumours, and that the effect of the drug is based on an increased inhibition of mitoses, a reduction of the excitatory reactions produced by irradiation and an increased incidence of damaged cells and of cells in the stages of division. It may be supposed, therefore, that the inhibitory effect of the drug for carcinogenesis induced by 4-dimethyl-aminoazobenzene is due to the delay in 